\section{Los servicios de sangre en la Región de las Américas}

José Ramiro Cruz, ${ }^{1}$ editor invitado

1 Organización Panamericana de la Salud, Laboratorio y Bancos de Sangre, Washington, D.C., Estados Unidos de América.
En los últimos años, los servicios de sangre en la Región de las Américas han mostrado grandes adelantos. Uno de ellos ha sido la actual disponibilidad de información estructurada acerca de los servicios de todos los países y territorios del continente americano, sin excepción alguna, lo cual nos permite no solo saber cómo han evolucionado dichos servicios, sino también identificar las deficiencias que aún quedan por subsanar. Otro adelanto notable es el haber logrado un mejor tamizaje para determinar la presencia de marcadores de infecciones que podrían transmitirse mediante la transfusión de las unidades de sangre recolectadas. En 1999, los países de América Latina y el Caribe no hispanoparlante notificaron haber recolectado 5996591 unidades de sangre, de las cuales $98,86 \%$ fueron sometidas al tamizaje del virus de la inmunodeficiencia humana (VIH); $98,71 \%$ al del virus de la hepatitis $\mathrm{B}, \mathrm{y}$ $94,33 \%$ al del virus de la hepatitis C. En 2001, el tamizaje del VIH tuvo una cobertura de 99,91\%; el del virus de la hepatitis B, de 99,87\%; y el del virus de la hepatitis C, de $99,12 \%$, a pesar de que el número de unidades donadas en América Latina y el Caribe había aumentado a 6831 001. Esta cifra representa un incremento de $14 \%$ en comparación con la de 1999. Aun así, la cantidad de sangre en los países de la Región continúa siendo insuficiente y es preciso redoblar los esfuerzos por lograr que toda la sangre donada sea sometida a un tamizaje para evitar la transmisión de enfermedades infecciosas.

Un logro adicional guarda relación con el cambio de filosofía que se ha producido en los servicios de sangre y en sus coordinadores en los países de América Latina y el Caribe. Mientras que anteriormente se hacía hincapié en la seguridad del producto transfundible, actualmente los profesionales nacionales han determinado que las prioridades son la suficiencia de la sangre y su disponibilidad para tratar a los pacientes oportunamente y con el mayor grado de seguridad y calidad posibles. La garantía de la calidad, la promoción de la donación voluntaria, altruista, repetida y no remunerada de sangre, la hemovigilancia o seguimiento de pacientes para determinar reacciones adversas a las transfusiones, incluida la transmisión de enfermedades infecciosas, y la valoración de la sangre como un recurso nacional se han convertido en los ejes estratégicos para el desarrollo de los sistemas nacionales de sangre.

El presente número de la Revista Panamericana de Salud Pública/Pan American Journal of Public Health tiene el propósito de ilustrar los logros y desafíos de los servicios de sangre en países americanos presentando el panorama regional, algunas experiencias nacionales y algunos aspectos metodológicos que pueden utilizarse como herramientas para enfrentar el futuro.

En el primero de los artículos, el Programa Regional de Servicios de Laboratorio y Sangre de la Organización Panamericana de la Salud resume los componentes básicos de un sistema nacional de sangre que son necesarios para orientar los procesos destinados a alcanzar la suficiencia, seguridad y calidad de la sangre para transfusión, así como el uso eficiente de los recursos nacionales. La expresión de estos componentes en los países puede apreciarse en los trabajos de Ballester Santovenia (p. 160) y de Fuentes Rivera Salcedo y Roca Valencia (p. 165), que versan sobre las experiencias en Cuba y Perú, respectivamente.

Los donantes son los pilares de la suficiencia y seguridad de la sangre. El artículo de García Gutiérrez et al. (p. 85) resume los hallazgos obtenidos en dos grandes áreas mediante estudios antropológicos realizados en 15 países de la Región. Dichas áreas son: 1) los conocimientos, actitudes y 
prácticas de la población con respecto a la donación de sangre y 2) el nivel de preparación de los servicios de sangre para atender a los posibles donantes. Los autores proponen utilizar los hallazgos a nivel nacional en programas de educación pública para promover la donación voluntaria de sangre, así como para introducir en los servicios de sangre cambios estructurales y funcionales que garanticen una buena atención a los donantes. La posibilidad de lograr, en un plazo relativamente corto, cambios importantes en la calidad de los donantes se demuestra en el trabajo de Gonçalez et al. (p. 144), quienes notifican un aumento de 20 a $57 \%$ en la proporción de donantes voluntarios altruistas en un período de seis años. Esta tendencia está asociada con una disminución del descarte de unidades de sangre obtenidas por los servicios, como lo demuestran los datos de Salles et al. (p. 111), especialmente cuando las personas donan sangre repetidamente.

El tamizaje cuidadoso de las unidades de sangre contribuye a su seguridad, tal como lo indican León et al. (p. 117), quienes encontraron que en el Banco Municipal de Sangre de Caracas, Venezuela, 0,2\% de las muestras eran positivas a HTLV I y II. Las pruebas para detectar estos dos virus no forman parte de la lista de exámenes requeridos por los Estándares de Trabajo para Bancos de Sangre, publicados por la Organización Panamericana de la Salud en 1999, pero sí están entre las pruebas que se recomienda evaluar para determinar si deben agregarse a dicha lista. Dado que un aumento de las pruebas de tamizaje redunda en una mayor inversión monetaria por parte de los servicios de sangre, también es importante determinar si las guías de tamizaje actuales son pertinentes, como lo hicieron Otani et al. (p. 172). Según estos investigadores, una sola prueba de electroinmunoensayo es suficiente para el tamizaje del VIH en la población estudiada.

La validez de la información obtenida en los servicios de sangre está estrechamente ligada con los procesos de garantía de calidad, descritos de forma general por Franco (p. 176). Cuatros artículos en este número especial —dos de Sáez-Alquezar et al. (pp. 91 y 129), uno de Beltrán Durán y Ayala Guzmán (p. 138) en Colombia, y uno de Oknaian et al. (p. 149) en Argentina-, presentan una perspectiva amplia de los procesos de evaluación externa del desempeño, tanto en el nivel regional como en el nacional. Es claro que este tipo de acción contribuye a mejorar la precisión de los resultados y permite identificar las debilidades de los sistemas. Son especialmente interesante los resultados observados en Colombia, donde se identificaron más imprecisiones en aquellos bancos de sangre con un menor volumen de trabajo.

Los escritos de Lobo et al. (p. 154) y de Fontes et al. (p. 124) ponen de manifiesto que los servicios de sangre en la Región funcionan como centros para el tratamiento de pacientes con hemofilia, hemoglobinopatías y otros trastornos, y no solo como servicios limitados a la transfusión. El establecimiento de guías de transfusión en cada centro de atención ha contribuido al buen ordenamiento de los procesos internos de los servicios. Salazar resume los principios de dichas guías en el último de los artículos (p. 183).

La situación general de la disponibilidad, calidad y seguridad de la sangre en la Región de las Américas se resume en el artículo de Cruz y PérezRosales (p. 103). En él se presentan datos de 43 países y territorios americanos y se ilustra el valor de la información proporcionada por las autoridades nacionales a la Organización Panamericana de la Salud. 